\title{
Variabilidade genética da raça Brahman no Brasil detectada por meio de análise de pedigree
}

\author{
Lydio Cosac de Faria( ${ }^{(1)}$, Sandra Aidar de Queiroz ${ }^{(2)}$, Pedro Alejandro Vozzi(3), Raysildo Barbosa Lôbo ${ }^{(3)}$, \\ Cláudio de Ulhôa Magnabosco(4) e João Ademir de Oliveira(5)
}

\begin{abstract}
(1)Associação dos Criadores de Brahman do Brasil, Praça Vicentino Rodrigues da Cunha, no 110, CEP 38.022-330 Uberaba, MG. E-mail: Iydiocf@yahoo.com.br ${ }^{(2)}$ Universidade Estadual Paulista (Unesp), Faculdade de Ciências Agrárias e Veterinárias (FCAV), Departamento de Zootecnia, Via de acesso Prof. Paulo Castellane, s/no, CEP 18884-900 Jaboticabal, SP. E-mail: saquei@fcav.unesp.br ${ }^{(3)}$ Associação Nacional de Criadores e Pesquisadores, Rua João Godoy, № 463, CEP 14020-330 Ribeirão Preto, SP. E-mail: ancp@ancp.org.br (4)Embrapa Cerrados, BR 020, Km 18, CP 08223, CEP 73.310-970 Planaltina, DF. E-mail: mclaudio@cpac.embrapa.br ${ }^{(5)}$ Unesp, FCAV, Departamento de Ciências Exatas. E-mail: jaoliv@fcav.unesp.br
\end{abstract}

Resumo - O objetivo deste trabalho foi analisar a variabilidade genética da raça Brahman no Brasil, por meio da análise de 15.851 pedigrees. O arquivo de dados foi dividido em dois períodos: 1998-2001 e 2002-2005. A variabilidade genética foi avaliada por parâmetros baseados na probabilidade de origem do gene: número efetivo de ancestrais, número efetivo de fundadores, número efetivo de genomas remanescentes e coeficientes de parentesco e de endogamia. Os valores encontrados quanto ao número de fundadores mostraram que a população está em expansão, embora o número efetivo de fundadores tenha diminuído de um período para outro. Os resultados foram diferentes em relação ao número de ancestrais e genomas remanescentes, que apresentaram crescimento de $23 \%$ nos períodos avaliados. O coeficiente de endogamia diminuiu nos períodos estudados, porém o coeficiente de parentesco "inter se" cresceu. Poucos ancestrais apresentaram grande contribuição genética para a população, o que evidencia a utilização de poucos indivíduos na reprodução. A raça Brahman, no Brasil, encontra-se em expansão, caracterizada pela diminuição do coeficiente de endogamia e aumento nos números efetivos de fundadores e de genótipos remanescentes. Entretanto, a variabilidade genética da raça mostra aumento do parentesco "inter se" e grande concentração do patrimônio genético de poucos indivíduos na população.

Termos para indexação: coeficiente de parentesco, endogamia, número efetivo de ancestrais, número efetivo de fundadores, número efetivo de genomas remanescentes.

\section{Genetic variability detection in Brahman cattle in Brazil trough pedigree analysis}

\begin{abstract}
This work aimed to analyse the genetic variability of Brahman breed in Brazil, through the analysis of 15,851 pedigrees. The data file was divided into two periods: $1998-2001$ and 2002-2005. The genetic variability was evaluated by the following parameters, based on the probability of gene origin: number of ancestors, effective number of founders, effective number of remaining genomes, and the relationship and inbreeding coefficients. The values for the number of founders showed that the population is expanding, although the effective number of founders has been reduced from one period to the other. The results were different for the number of ancestors and the remaining genomes, which grew by $23 \%$ in the studied periods. The inbreeding coefficient decreased in the studied periods, but the "inter se" relationship coefficient increased. Few ancestors showed great genetic contribution to the population, which indicates the use of small number of individuals in the reproduction. Brahman breed population in Brazil is expanding, characterized by the decreasing of the inbreeding coefficients and the increasing of the effective number of ancestors and remaining genotypes. Nevertheless, the breed genetic variability shows increasing "inter se" relationships and a great concentration of gene heritage of few individuals in the population.
\end{abstract}

Index terms: relationship coefficient, inbreeding, effective number of ancestors, effective number of founders, effective number of remaining genomes.

\section{Introdução}

Um programa de melhoramento genético eficaz proporciona propagação de alelos desejáveis, e os avanços nas tecnologias reprodutivas, como inseminação artificial, ovulação múltipla, transferência de embriões e produção in vitro de embriões podem permitir a aplicação de alta intensidade de seleção, tanto em machos quanto em fêmeas, e contribuir para um rápido progresso genético (Kinghorn, 2000). Um pequeno e seleto número de indivíduos é capaz de deixar uma grande progênie, mas a disseminação intensiva do material genético melhorado pode levar à redução da diversidade genética (Van der Werf, 2000).

Pesq. agropec. bras., Brasília, v.45, n.10, p.1133-1140, out. 2010 
O fluxo de genes na população, considerando-se um sistema piramidal, é determinado pela transferência de genes dos núcleos de seleção, caracterizados pela contribuição genética de poucos indivíduos aos rebanhos multiplicadores e comerciais (Carneiro et al., 2009). Logo, com a implementação de programas de melhoramento genético e o emprego de modernas tecnologias reprodutivas, a estrutura genética de uma população pode ter, como consequência, uma contribuição genética desigual e prolongada de alguns reprodutores. Isto, associado à permanência desses mesmos reprodutores por longos períodos nas centrais de inseminação, pode causar aumentos no intervalo de geração e nos níveis de endogamia dos rebanhos, com consequente decréscimo no ganho genético. Estima-se que aproximadamente $50 \%$ dos mais de 5.000 touros jovens da raça Holandesa, submetidos anualmente a testes de progênie no mundo, sejam filhos de dez touros, usados de forma intensiva em diferentes países (Weigel, 2001).

Um dos caminhos para descrever a variabilidade genética e sua evolução no tempo é a análise de informações contidas nos pedigrees dos animais (Boichard et al., 1997). O método proposto por Lacy (1989), para populações de animais de programas de conservação, e por Boichard et al. (1997), para populações bovinas selecionadas, foi aplicado com sucesso na análise de diversidade genética de raças bovinas francesas e austríacas (Maignel et al., 1996; Sölkner et al., 1998) e em raças zebuínas no Brasil (Faria et al., 2004, 2009; Vozzi et al., 2006). Os parâmetros baseados na probabilidade de origem do gene, como os números efetivos de fundadores, de ancestrais e de genomas remanescentes, são úteis para descrever a estrutura genética populacional da raça após um pequeno número de gerações (Vozzi et al., 2006).

A raça bovina Brahman teve sua origem no século XIX, no Sul dos Estados Unidos da América, a partir do cruzamento entre indivíduos das raças Nelore, Gir, Guzerá e Krishna Valley (Faria, 2006). No Brasil, sua introdução ocorreu em 1994, com a importação de animais originários dos Estados Unidos e, posteriormente, da Argentina, Colômbia e Paraguai, no total de 976 animais vivos, que entraram no país até abril de 1994 (Associação Brasileira de Criadores de Zebu, 2010). Desde sua introdução, a raça está em constante crescimento, o que pode ser observado por meio de dados estatísticos da Associação Brasileira dos Criadores de Zebu (ABCZ). No período de
1995 a 2009, o volume de registros genealógicos de nascimento cresceu, em média, $129 \%$ ao ano, e o total de animais com registro definitivo nesse período é de aproximadamente 64 mil indivíduos (Associação Brasileira de Criadores de Zebu, 2010). A expansão desse recurso genético vem sendo feita, principalmente, por meio do uso de sêmen, de fertilização in vitro e de transferências de embriões, além da realização de cruzamentos absorventes de fêmeas das raças Nelore e Guzerá com touros Brahman PO e POI (Associação Brasileira de Criadores de Zebu, 2010). Entretanto, em razão de sua recente introdução no país, poucos estudos foram efetuados com essa raça, e não foram localizadas pesquisas referentes à análise da variabilidade genética presente nessa população, com o intuito de subsidiar a elaboração de diretrizes ao programa de melhoramento da raça.

O objetivo deste trabalho foi analisar a variabilidade genética da população de bovinos Brahman no Brasil, por meio da análise dos dados de 15.851 pedigrees, obtidos junto à Associação Nacional de Criadores e Pesquisadores, dos períodos de introdução (19982001) e expansão (2002-2005) da raça.

\section{Material e Métodos}

Foram utilizados dados de pedigree do Programa de Melhoramento Genético da Raça Brahman (PMGRB), gerido pela Associação Nacional de Criadores e Pesquisadores (2010), em Ribeirão Preto, SP.

O conjunto de dados proveio de 16 rebanhos participantes do PMGRB, criados nos estados de São Paulo, Minas Gerais, Mato Grosso, Mato Grosso do Sul, Tocantins e Goiás (Tabela 1). A maioria das fazendas, ao ingressar no PMGRB, adotou estação de acasalamentos, cuja duração variava de 60 a 90 dias, no período de outubro a março, conforme a região e o nível de manejo do rebanho. A utilização de técnicas de reprodução, como inseminação artificial, fertilização in vitro e transferência de embriões, como também repasse de touros após a primeira ou segunda oportunidade de acasalamento, foram práticas comuns nos rebanhos analisados. Essas informações foram submetidas a rigorosa averiguação, antes de serem incorporados ao arquivo de dados, e foram eliminadas aquelas discrepantes e biologicamente incorretas.

As fazendas participantes do programa tinham manejos diferenciados de acordo com as atividades realizadas em cada uma, pois alguns criadores 
participam de exposições e leilões de elite. Assim, alguns rebanhos foram manejados exclusivamente em pastagens, outros em pastagens e suplementados, ou em pastagens e confinados (Tabela 1). As pastagens mais comuns eram compostas por gramíneas dos gêneros Urochloa, Andropogon, Panicum e Cynodon. Alguns criadores adotaram técnicas de adubação e irrigação de pastagens, com pastejo rotacionado. Nos locais das fazendas ocorrem os tipos climaticos Aw e $\mathrm{Cw}$ de Köppen.

$\mathrm{O}$ arquivo de dados analisado continha informações de 15.851 pedigrees, referentes aos animais nascidos de 1998 a 2005, cadastrados no PMGRB, no total de 35.180 indivíduos. As informações incluídas no arquivo foram: animal, pai, mãe, sexo, raça, ano de nascimento e nome do animal. Os parâmetros baseados na probabilidade de origem do gene e os coeficientes de parentesco e endogamia foram estimados por meio da utilização do pacote Pedig (Boichard, 2002), em dois períodos, de 1998 a 2001 e de 2002 a 2005, buscandose caracterizar os períodos de introdução e de expansão da raça Brahman no Brasil, respectivamente.

O coeficiente de endogamia (F) de um indivíduo foi calculado segundo a definição de Malécot (1948), ou seja, como a probabilidade de que dois genes presentes no indivíduo em um dado loco sejam idênticos por descendência, isto é, igual ao coeficiente de parentesco de seus pais. O coeficiente de parentesco foi obtido de acordo com a definição de Wright (1921).

Tabela 1. Distribuição de bovinos da raça Brahman, de acordo com rebanho, estado da federação e tipo de manejo.

\begin{tabular}{lccccc}
\hline Estado & Rebanho & \multirow{2}{*}{ o total } & \multicolumn{3}{c}{ № de animais por tipo de manejo } \\
\cline { 4 - 6 } & & & Pasto & Semi-intensivo & Intensivo \\
\hline GO & 1 & 75 & 23 & 30 & 22 \\
MG & 2 & 59 & 59 & 0 & 0 \\
MG & 3 & 1.102 & 604 & 403 & 95 \\
MG & 4 & 64 & 54 & 2 & 8 \\
MS & 5 & 139 & 139 & 0 & 0 \\
MS & 6 & 552 & 543 & 9 & 0 \\
MS & 7 & 284 & 193 & 36 & 55 \\
MT & 8 & 3.403 & 3.200 & 155 & 48 \\
MT & 9 & 5.134 & 4.830 & 291 & 13 \\
SP & 10 & 35 & 35 & 0 & 0 \\
SP & 11 & 70 & 70 & 0 & 0 \\
SP & 12 & 926 & 670 & 177 & 79 \\
SP & 13 & 3.193 & 2.381 & 504 & 308 \\
SP & 14 & 420 & 52 & 268 & 100 \\
SP & 15 & 43 & 21 & 0 & 22 \\
TO & 16 & 352 & 280 & 8 & 64 \\
\hline
\end{tabular}

O número médio de gerações, que quantifica a contribuição dos principais reprodutores, foi definido pela soma, entre todas as gerações, da proporção de ancestrais identificados em cada geração.

$\mathrm{O}$ tamanho efetivo da população $\left(\mathrm{N}_{\mathrm{e}}\right)$ foi estimado por meio da taxa de variação dos coeficientes médios de endogamia, entre os períodos estudados, que conforme Falconer \& Mackay (1996), é dada por:

$$
\Delta \mathrm{F}=\frac{\left(\mathrm{F}_{\mathrm{t}}-\mathrm{F}_{\mathrm{t}-1}\right)}{\left(1-\mathrm{F}_{\mathrm{t}-1}\right)}
$$

em que: $F_{t}$ é o coeficiente médio de endogamia, estimado no segundo período; $\mathrm{F}_{\mathrm{t}-1}$ é o coeficiente médio de endogamia, estimado no primeiro período, que resulta em:

$$
\mathrm{N}_{\mathrm{e}}=\frac{1}{2 \Delta \mathrm{F}}
$$

O número efetivo de fundadores $\left(\mathrm{N}_{\text {fun }}\right)$, que representa o número de animais com igual contribuição e que produziria a mesma variabilidade genética encontrada na população estudada, foi obtido como:

$$
\mathrm{N}_{\text {fun }}=\frac{1}{\Sigma \mathrm{p}_{\mathrm{i}}^{2}},
$$

em que: $p_{i}$ é a proporção de alelos da população de referência contribuída pelo i-ésimo fundador (Lacy, 1989).

A determinação do número efetivo de ancestrais $\left(\mathrm{N}_{\mathrm{anc}}\right)$, que representa o mínimo de ancestrais, fundadores ou não, necessários para se explicar a diversidade genética total da população estudada, foi obtida por:

$$
\mathrm{N}_{\mathrm{anc}}=\frac{1}{\Sigma \mathrm{p}_{\mathrm{k}}^{2}}
$$

em que: $p_{k}$ é a contribuição marginal do k-ésimo ancestral na população (Boichard et al., 1997).

$\mathrm{O}$ número efetivo de genomas remanescentes $\left(\mathrm{N}_{\text {gen }}\right)$, ou seja, o número de fundadores com igual contribuição que não ocasionaria perda de alelos fundadores e que produziria a mesma diversidade genética encontrada na população, foi estimado como:

$$
\mathrm{N}_{\text {gen }}=\frac{1}{\Sigma\left(\mathrm{p}_{\mathrm{i}}^{2} / \mathrm{r}_{\mathrm{i}}\right)}
$$


em que: $r_{\mathrm{i}}$ é a proporção esperada de alelos do i-ésimo fundador que permaneceria na população referência; e $p_{i}$ é a proporção esperada de alelos do i-ésimo fundador que contribuiu para a população referência (Lacy, 1989).

$\mathrm{O} \mathrm{N}_{\text {fun }}$ avalia a contribuição do patrimônio genético dos fundadores entre as gerações, por meio da reprodução, levando-se em consideração a seleção e o tamanho de família. No entanto, ao se estimar $\mathrm{N}_{\text {anc }}$, é considerado o decréscimo do número de reprodutores em determinado período, que é uma das causas da perda de genes nas populações, enquanto $\mathrm{N}_{\text {gen }}$ avalia o número de genes fundadores para determinado loco, que é mantido na população.

A dimensão da deriva genética foi obtida por $\mathrm{N}_{\text {gen }} / \mathrm{N}_{\text {fun. }}$. Quanto menor o valor dessa razão, maior esse processo. Deriva genética é o nome que se dá à alteração das frequências alélicas de uma população de pequeno tamanho, em razão unicamente do acaso, a qual ocorre com maior intensidade quando a população sofre uma redução drástica do seu tamanho efetivo (Falconer \& Mackay, 1996).

A integralidade do pedigree foi calculada somente para indivíduos com pelo menos um progenitor conhecido (Boichard, 2002), de acordo com o sexo e ano do nascimento do animal, pelo método proposto por MacCluer et al. (1983) por:

$$
I_{d}=\frac{2 I_{d_{p a t}} I_{d_{\text {mat }}}}{I_{d_{\text {pat }}}+I_{d_{\text {mat }}}} \quad \text { e } \quad I_{d_{k}}=\frac{1}{d} \sum_{i=1}^{d} a_{i}
$$

em que: d é o número de gerações consideradas no cálculo do pedigree; $\mathrm{k}$ representa a linha paterna (pat) ou materna (mat) de um indivíduo; e $\mathrm{a}_{\mathrm{i}}$ é a proporção de ancestrais conhecidos na geração i. A integralidade do pedigree corresponde à proporção média de pedigree completo, para cada geração por ano, cujos valores variam de 0 a 1 . Assim, se todos os ancestrais de um indivíduo em uma geração específica são conhecidos, $\mathrm{I}=1$, caso contrário, $0 \leq \mathrm{I}<1$.

\section{Resultados e Discussão}

O número médios de gerações, obtido no período de 1994 a 2005, foi igual a 2,26 e 1,83, para machos e fêmeas, respectivamente, e o número máximo para ambos os sexos foi proximo de 3 (Figura 1), o que evidencia a recente introdução da raça no país. Do total de 15.851 pedigrees analisados, $49 \%$ são de machos e $51 \%$ de fêmeas. O número médio de filhos por touro foi 23,23 , enquanto as fêmeas, em média, tiveram 1,98 filhos. Faria et al. (2004) pesquisaram a raça Sindi e encontraram número máximo de seis gerações para ambos os sexos, enquanto Faria et al. (2009) analisaram dados da Associação Brasileira de Criadores de Zebu (ABCZ) e relataram 10, 12 e 13 gerações, respectivamente, para as raças Gir, Guzerá e Nelore, entre os anos de 1979 e 1998.

Considerando-se o período estudado de 12 anos (1994-2005), pode-se calcular os intervalos médios de geração, de machos e fêmeas de bovinos Brahman, em aproximadamente cinco e seis anos. $\mathrm{O}$ intervalo de geração mede o tempo médio de permanência dos mesmos genes na população e é inversamente proporcional ao ganho genético, ou seja, quanto maior o intervalo, menor o ganho. Esses resultados foram menores do que os mencionados por Queiroz \& Lôbo (1993), que relataram valor de 8,02 anos para a raça Gir, por Faria et al. (2009), que reportaram intervalo de oito anos para as raças Nelore, Gir e Guzerá, e por Carneiro et al. (2009), que estimaram o intervalo em 7,23 anos na raça Indubrasil. No entanto, o valor obtido para a raça Brahman ficou acima dos intervalos estimados por

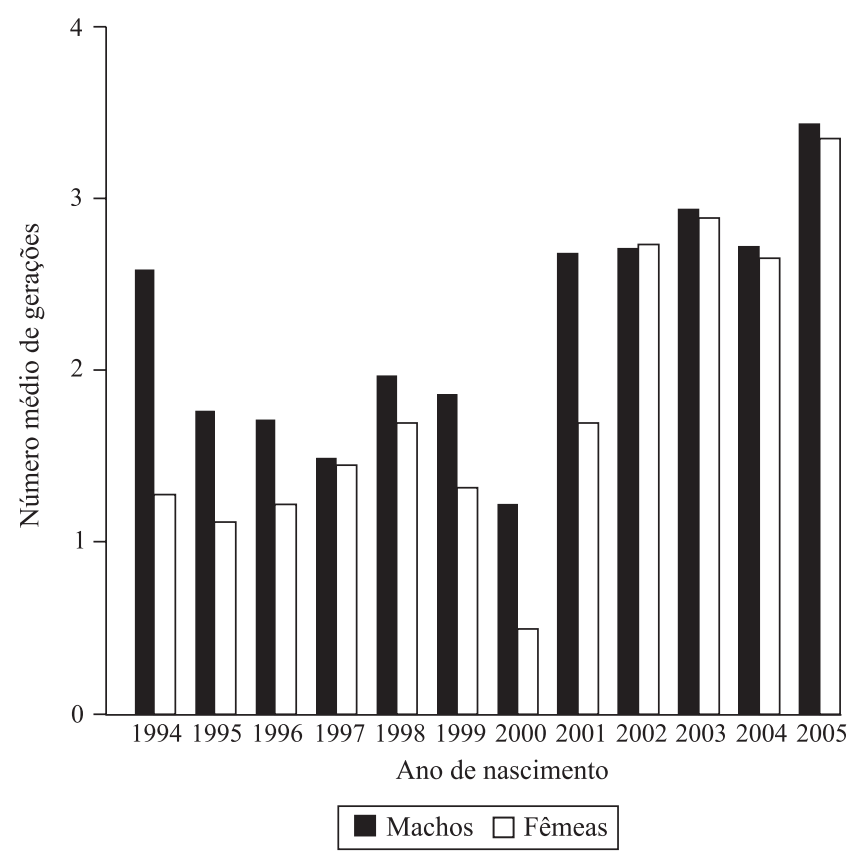

Figura 1. Número médio de gerações, de acordo com sexo e ano de nascimento de bovinos da raça Brahman. 
Razook et al. (1993), de 3,66 e 3,74 anos, para bovinos Nelore e Guzerá, respectivamente.

A integralidade do pedigree (I) foi apresentada até a sexta geração (Tabela 2). A partir daí, os valores de I foram próximos de zero. A estimativa de I é importante, pois o coeficiente de endogamia (F) de um indivíduo depende de quanto sua ascendência é conhecida, de modo que, quanto maior for esse conhecimento, mais confiável será seu $\mathrm{F}$ estimado em relação à base populacional estudada. Observa-se que os valores médios de I, em todas as gerações, cresceram no decorrer dos anos, o que indica melhora na qualidade das informações genealógicas, com exceção dos valores referentes ao ano 2000 (Tabela 2). Esse resultado pode ser atribuído ao acréscimo acentuado de animais que ingressaram no programa de melhoramento nesse ano, possivelmente com pedigrees incompletos. Em geral, os resultados de integralidade indicam que o controle de informações genealógicas dos rebanhos Brahman, considerando-se a recente introdução da raça no país, é de razoável qualidade, com várias gerações controladas.

O coeficiente de endogamia médio, estimado no primeiro período estudado (1998-2001), em 7.291 animais, foi igual a $0,69 \%$ com $\mathrm{F}$ máximo de $25 \%$, valor maior de que o do segundo periodo (20022005), estimado em 8.560 animais, que foi de $0,42 \%$ com $\mathrm{F}$ máximo de $37,5 \%$. A percentagem de animais endogâmicos decresceu do primeiro para o segundo período de 13,24 a $10,71 \%$, o que representa pequena queda da endogamia. $O$ decréscimo da endogamia, em torno de $0,27 \%$, embora pequeno, se deve, provavelmente, ao aumento populacional da raça e, consequentemente, ao incremento de animais novos na população, além da possível inclusão de animais sem pedigree conhecido no programa. Esses resultados são corroborados pelos apresentados na Tabela 2 .

Do total de 35.180 animais presentes no arquivo de genealogia, $5.170(14,69 \%)$ tiveram coeficiente de endogamia (F) diferente de zero (Tabela 3 ) e estimativa de $\mathrm{F}$ médio igual a $3,43 \%$, com valor máximo de $37,5 \%$. Embora tenha ocorrido diminuição no número de animais endogâmicos, a percentagem de animais com $\mathrm{F}$ maior que zero foi relativamente alta, isto é, $14,7 \%$ tiveram algum grau de endogamia, o que indica o acasalamento de indivíduos aparentados. Isto pode ter acarretado alguma diminuição da variabilidade genética da população estudada. Entretanto, a grande maioria dos animais endogâmicos $(83,85 \%)$ na população teve F de pequena magnitude (até 5\%) (Tabela 3).

Oliveira et al. (1999) estudaram a raça Guzerá, em um rebanho isolado, e obtiveram valores de $\mathrm{F}$ médio de 1,08 e 1,36\%, para machos e fêmeas, respectivamente. Resultados também superiores aos encontrados no presente trabalho foram obtidos por Faria et al. (2009), que avaliaram dados da Associação Brasileira de Criadores de Zebu (ABCZ) e relataram aumento no coeficiente médio de endogamia no decorrer dos anos (1979-1998), que alcançaram valores de 2,13, 2,28 e $1,75 \%$, respectivamente, para as raças Nelore, Gir e Guzerá.

Os coeficientes de parentesco médios entre os indivíduos da população (parentesco "inter se") da raça Brahman foram iguais a 3,6 e 4,8\%, respectivamente, no primeiro e segundo períodos. Esses valores foram superiores aos estimados por Queiroz \& Lôbo (1993), na raça Gir, e denotam a necessidade de se monitorarem os acasalamentos entre os animais dessa raça, para evitar acasalamentos entre indivíduos aparentados e restringir os acasalamentos entre parentes, pela fixação

Tabela 2. Média da integralidade (I) do pedigree, até a sexta geração, por ano de nascimento de bovinos da raça Brahman.

\begin{tabular}{lcccccccccc}
\hline Ano & NM & NF & NG & NA & $\begin{array}{c}\text { Primeira } \\
\text { geração }\end{array}$ & $\begin{array}{c}\text { Segunda } \\
\text { geração }\end{array}$ & $\begin{array}{c}\text { Terceira } \\
\text { geração }\end{array}$ & $\begin{array}{c}\text { Quarta } \\
\text { geração }\end{array}$ & $\begin{array}{c}\text { Quinta } \\
\text { geração }\end{array}$ & $\begin{array}{c}\text { Sexta } \\
\text { geração }\end{array}$ \\
\hline 1998 & 300 & 844 & 1,84 & 16,9 & 0,59 & 0,43 & 0,39 & 0,28 & 0,08 & 0,02 \\
1999 & 707 & 1.189 & 1,59 & 14,7 & 0,54 & 0,35 & 0,30 & 0,23 & 0,08 & 0,02 \\
2000 & 1.797 & 7.220 & 0,86 & 8,3 & 0,29 & 0,17 & 0,12 & 0,09 & 0,03 \\
2001 & 976 & 1.521 & 2,19 & 28,4 & 0,70 & 0,43 & 0,39 & 0,29 & 0,17 \\
2002 & 1.485 & 2.375 & 2,23 & 31,4 & 0,71 & 0,45 & 0,35 & 0,29 & 0,18 \\
2203 & 2.140 & 1.929 & 2,92 & 41,9 & 0,96 & 0,62 & 0,49 & 0,39 & 0,26 \\
2004 & 3.375 & 3.194 & 2,69 & 38,2 & 0,99 & 0,53 & 0,41 & 0,34 & 0,23 \\
2005 & 954 & 984 & 3,40 & 54,0 & 0,99 & 0,72 & 0,57 & 0,50 & 0,21 \\
\hline Total & 11.734 & 19.256 & & & & & & & 0,11 & 0,37 \\
\hline
\end{tabular}

NM, número de machos; NF, número de fêmeas; NG, número médio de gerações conhecidas; NA, número médio de ancestrais por indivíduo. 
de um valor máximo para o coeficiente de endogamia esperado.

O tamanho efetivo estimado $\left(\mathrm{N}_{\mathrm{e}}\right)$ para a população Brahman foi de aproximadamente 184 indivíduos. Este valor representa o tamanho da população geneticamente ativa, isto é, que poderia gerar a mesma taxa de endogamia ou variância nas frequências alélicas, como a observada na população sob consideração, caso esses animais fossem criados nas condições de uma população idealizada (Falconer \& Mackay, 1996). Faria et al. (2009) estimaram valores menores para populações das raças Nelore, Gire Guzerá, que variaram de 45 a 117. Essas raças são mais tradicionais e com maior expressão comercial no Brasil. Meuwissen \& Woollians (1994) sugeriram tamanho efetivo entre $31 \mathrm{e}$ 250, para prevenir declínio nos valores adaptativos dos animais como consequência da depressão endogâmica, intervalo esse que inclui o resultado observado no presente trabalho.

Houve aumento de aproximadamente 2,5 vezes no número de fundadores (animais com progênie, mas sem ascendência conhecida), no segundo período considerado (2002-2005), em relação ao primeiro (Tabela 4), o que pode ser explicado pela expansão da

Tabela 3. Frequência de bovinos endogâmicos da raça Brahman, de acordo com a classe de endogamia (F).

\begin{tabular}{lc}
\hline Classe de endogamia (F \%) & Número de animais \\
\hline $0-5$ & 4.335 \\
$5-10$ & 285 \\
$10-15$ & 177 \\
$15-20$ & 8 \\
$20-25$ & 353 \\
$25-30$ & 1 \\
$30-35$ & 11 \\
\hline Total & 5.170 \\
\hline
\end{tabular}

F médio dos animais endogâmicos: $3,43 \%$.

Tabela 4. Estimativas de parâmetros, baseadas na probabilidade de origem do gene na raça Brahman, por período.

\begin{tabular}{lcc}
\hline Período & $1998-2001$ & $2002-2005$ \\
\hline Número de fundadores $^{(1)}$ & 3.164 & 7.973 \\
$\mathrm{~N}_{\text {fun }}$ & 718,3 & 183,3 \\
$\mathrm{~N}_{\text {anc }}$ & 41,0 & 50,2 \\
$\mathrm{~N}_{\text {gen }}$ & 33,2 & 40,9 \\
\hline
\end{tabular}

${ }^{(1)}$ Número de fundadores, animais com progênie, mas sem ascendência conhecida; $\mathrm{N}_{\text {fun }}$, número efetivo de fundadores; $\mathrm{N}_{\mathrm{anc}}$, número efetivo de ancestrais; $\mathrm{N}_{\text {gen }}$, número efetivo de genomas remanescentes. raça no Brasil na época. Essa expansão está associada à incorporação, no programa de melhoramento genético, de animais registrados no livro aberto da raça, com poucas gerações de ancestrais conhecidos, oriundos de cruzamentos absorventes, em que foram usadas matrizes das raças Nelore e Guzerá com touros Brahman PO ou POI.

Houve diminuição nos valores dos parâmetros estimados, em ambos os períodos, que exprimem redução na variabilidade na seguinte ordem: $\mathrm{N}_{\text {fun }}>\mathrm{N}_{\text {anc }}>\mathrm{N}_{\text {gen }}$ (Tabela 4).

As estimativas de $\mathrm{N}_{\text {fun }}$ foram maiores, por expressar apenas a contribuição de fundadores, e as de $\mathrm{N}_{\text {gen }}$ menores, por levar em conta todas as possibilidades de perdas de alelos fundadores. A representação de fundadores nos animais analisados, demonstrada

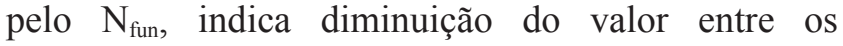
períodos estudados, apesar de o valor referente ao último período ser também relativamente alto. Essa diminuição pode ser consequência da maior utilização de poucos indivíduos ou do fato de alguns indivíduos terem deixado maior número de descendentes do que outros, isto é, tiveram maior sucesso reprodutivo. A presença de animais de outras raças zebuínas, como Nelore e Guzerá, como fundadores pode também explicar os valores estimados para o parâmetro $\mathrm{N}_{\text {fun }}$. Segundo Boichard et al. (1997), a presença de algumas gerações com informações incompletas de pedigree pode superestimar o $\mathrm{N}_{\text {fun }}$. No presente trabalho, o número de fundadores (animais com ambos os pais desconhecidos) foi alto, o que caracteriza a presença de pedigrees incompletos. Assim, o valor obtido para $\mathrm{N}_{\text {fun }}$ pode estar superestimado. Entretanto, em razão da recente introdução da raça Brahman no país, esses resultados eram esperados.

Os valores estimados para o número efetivo de ancestrais $\left(\mathrm{N}_{\mathrm{anc}}\right)$ indicam intenso uso de poucos reprodutores, nos dois períodos estudados (Tabela 4), provavelmente em consequência de predominância de inseminação artificial, produção in vitro e transferência de embriões, resultado confirmado pela contribuição marginal acumulada dos principais ancestrais da raça Brahman, em que se constata que apenas dez reprodutores contribuíram com aproximadamente 30\% dos genes, em cada período de referência (Tabela 5). Observou-se pequeno crescimento no número efetivo de genomas remanescentes $\left(\mathrm{N}_{\text {gen }}\right)$, estimado entre os dois períodos (Tabela 4), provavelmente em 
virtude do aumento de alelos fundadores entre 2002 e 2005. De modo similar ao observado em relação ao parâmetro $\mathrm{N}_{\text {anc }}$, o número de genomas remanescentes $\left(\mathrm{N}_{\text {gen }}\right)$ foi maior no último período considerado, mas as proporções entre $\mathrm{N}_{\text {gen }}$ e $\mathrm{N}_{\text {anc }}$, de aproximadamente $81 \%$, foram semelhantes nos dois períodos.

Os valores de diversidade genética na raça, representados pelo $\mathrm{N}_{\text {anc }}$, foram menores do que os encontrados por Perez Torrecillas et al. (2002) nas raças italianas Chianina e Maremmana, e por Boichard et al. (1997) na raça Simental, na França, a qual apresentou o maior valor de $\mathrm{N}_{\text {anc }}$ relatado na literatura consultada. Neste último caso, as fazendas, em sua maioria, utilizavam monta natural. No Brasil, Faria et al. (2009) relataram, em trabalho com raças zebuínas, que os valores de $\mathrm{N}_{\text {anc }}$ tenderam a decrescer no decorrer de quatro períodos, entre 1979 e 1998, de 80 a 34, 301 a 211 e 365 a 166, para as raças Nelore, Gir e Guzerá, respectivamente. Vozzi et al. (2006) reportaram como 70 a estimativa de $\mathrm{N}_{\text {anc }}$ para a raça Nelore, no ano de 2002.

Os valores encontrados no presente trabalho para a razão $\mathrm{N}_{\text {fun }} / \mathrm{N}_{\text {anc }}$ foram 17,5 e 3,7, no primeiro e segundo períodos estudados, respectivamente, o que caracteriza diminuição no número de reprodutores ao longo dos períodos, em consequência da utilização de poucos indivíduos por meio de inseminação artificial e outras técnicas reprodutivas. Esse resultado indica, provavelmente, perda de alelos na população e, consequentemente, redução da diversidade genética do suprimento gênico original. Processo inverso foi observado por Vercesi Filho et al. (2002) na raça Tabapuã, cuja razão passou de 1,02 a 1,44 ao longo dos anos. Boichard et al. (1997) relataram, sobre a raça Normanda, razão igual a 3, também atribuída à intensa utilização de poucos animais, pelo uso da inseminação artificial.

Poucos reprodutores foram responsáveis pela variação genética na população participante do

Tabela 5. Contribuição marginal acumulada (\%) dos principais ancestrais da raça Brahman, por período.

\begin{tabular}{lcc}
\hline Período & \multicolumn{2}{c}{ Proporção da contribuição de alelos } \\
\cline { 2 - 3 } & $1998-2001$ & $2002-2005$ \\
\hline Principal ancestral & 14,53 & 11,33 \\
Primeiros 5 ancestrais & 23,49 & 24,48 \\
Primeiros 10 ancestrais & 28,78 & 33,80 \\
Primeiros 50 ancestrais & 41,32 & 49,80 \\
\hline
\end{tabular}

programa de melhoramento genético dessa raça (Tabela 5). Nos últimos quatro anos, dez reprodutores responderam por quase $34 \%$ dos alelos presentes na população, e o principal ancestral contribuiu com mais de $10 \%$ dos genes, em cada período considerado. A elevada utilização de poucos ancestrais, nos períodos analisados, pode ter sido responsável pela elevação do parentesco médio entre os animais da população, o que levaria ao aumento da endogamia na população estudada, à perda de alelos fundadores por deriva genética e, consequentemente, à redução da variabilidade genética.

A razão $\mathrm{N}_{\text {gen }} / \mathrm{N}_{\text {fun }}$ indica a dimensão da deriva genética: quanto menor o seu valor, maior esse processo. Os valores obtidos no presente trabalho para a raça Brahman, nos períodos de anos subsequentes, aumentaram de 0,05 , no primeiro, para 0,22 , no segundo, o que indica uma diminuição da deriva genética, embora ambos os valores mostrem participação importante dessa raça na variabilidade genética da população avaliada. Processo inverso foi observado por Faria et al. (2004) na raça Sindi, cujos valores decresceram de 0,81 a 0,43 , o que indica aumento da deriva genética ao longo de quatro períodos. Na raça Tabapuã, Vercesi Filho et al. (2002) relataram a razão de 0,54 , no período de cinco anos.

Apesar de se tratar de pesquisa preliminar sobre a população de bovinos Brahman no Brasil, por incluir apenas rebanhos pertencentes ao extrato elite, os resultados do presente trabalho indicam que, embora essa raça esteja em expansão, há necessidade de monitoramento da diversidade genética, mediante o controle de acasalamentos entre indivíduos aparentados e o uso de maior número de reprodutores de diferentes origens, para evitar que, no futuro, o progresso genético quanto a características de importância econômica seja comprometido pela perda de variabilidade genética.

\section{Conclusões}

1. A raça Brahman no Brasil encontra-se em expansão, caracterizada pela diminuição do coeficiente de endogamia e aumento nos números efetivos de fundadores e de genótipos remanescentes, entre os períodos de introdução e expansão da raça.

2. A variabilidade genética, nos rebanhos analisados, apresenta aumento do parentesco "inter se" e grande concentração do patrimônio genético de poucos indivíduos na raça. 


\section{Referências}

ASSOCIAÇÃO BRASILEIRA DE CRIADORES DE ZEBU. Estatíticas. 2010. Disponível em: <http://www.abcz.org.br/ conteudo/tecnica/estatisticas.html>. Acesso em: 21 set. 2010.

ASSOCIAÇÃO NACIONAL DE CRIADORES E PESQUISADORES. Programa de melhoramento genético da raça Brahman. 2006. Disponível em: <http://www.ancp.org.br>. Acesso em: 20 jan. 2006.

BOICHARD, D. Pedig: a fortran package for pedigree analysis suited for large populations. In: WORLD CONGRESS ON GENETICS APPLIED TO LIVESTOCK PRODUCTION, 7., 2002, Montpellier. Proceedings. Montpellier: Institut National de la Recherche Agronomique, 2002. p.13-28.

BOICHARD, D.; MAIGNEL, L.; VERRIER, É. The value of using probabilities of gene origin to measure genetics variability in a population. Genetic, Selection and Evolution, v.29, p.5-23, 1997.

CARNEIRO, P.L.S.; MALHADO, C.H.M.; MARTINS FILHO, R.; CARNEIRO, A.P.S.; SILVA, F.F. e; TORRES, R. de A. A raça Indubrasil no Nordeste brasileiro: melhoramento e estrutura populacional. Revista Brasileira de Zootecnia, v.38, p.2327-2334, 2009.

FALCONER, D.S.; MACKAY, T.F.C. Introduction to quantitative genetics. $4^{\text {th }}$ ed. London: Longman Group, 1996. 464p.

FARIA, F.J.C.; VERCESI FILHO, A.E.; MADALENA, F.E.; JOSAHKIAN, L.A. Estrutura genética da raça Sindi no Brasil. Revista Brasileira de Zootecnia, v.33, p.852-857, 2004.

FARIA, F.J.C.; VERCESI FILHO, A.E.; MADALENA, F.E.; JOSAHKIAN, L.A. Pedigree analysis in the Brazilian Zebu breeds. Journal of Animal Breeding and Genetics, v.126, p.148-153, 2009 .

FARIA, L.C. Estudo genético quantitativo de características de crescimento e reprodutivas em bovinos da raça Brahman no Brasil. 2006. 117p. Dissertação (Mestrado) - Universidade Estadual Paulista, Jaboticabal.

KINGHORN, B. Boosting fecundity - the roles and value of AI, MOET, oocyte pickup and IFV in animal breeding. In: KINGHORN, B.; VAN DER WERF, J.; RYAN, M. (Ed.). Animal breeding: use of new technologies. Armidale: University of New England, 2000. p.199-212.

LACY, R.C. Analysis of founder representation in pedigree: founder equivalents and founder genome equivalents. Zoo Biology, v.8, p.111-123, 1989.

MACCLUER, J.W.; BOYCE, A.J.; DYKE, B.; WEITKAMP, L.R.; PFENNIG, D.W.; PARSONS, C.J. Inbreeding and pedigree structure in Standardbred. Journal of Heredity, v.74, p.394-399, 1983.
MAIGNEL, L.; BOICHARD, D.; VERRIER, E. Genetic variability of French dairy breeds estimated from pedrigree information. Interbull Bull, v.14, p.49-54, 1996.

MALÉCOT, G. Les mathématiques de l' hérédité. Paris: Mason et Cie, 1948. 60p.

MEUWISSEN, T.H.E.; WOOLLIAMS, J. Effective sizes of livestock populations to prevent a decline in fitness. Theoretical and Applied Genetics, v.89, p.1019-1026, 1994.

OLIVEIRA, J.A.; BASTOS, J.F.P.; TONHATI, H. Endogamia em um rebanho da raça Guzerá. Revista Brasileira de Zootecnia, v.28, p.721-728, 1999.

PÉREZ TORRECILLAS, C.; BOZZI, R.; NEGRINI, R.; FILIPPINI, F.; GEORGETTI, A. Genetic variability of tree Italian cattle breeds determined by parameters based on probabilities of gene origin. Journal of Animal Breeding and Genetics, v.119, p.274-279, 2002.

QUEIROZ, S.A.; LÔBO, R.B. Genetic relationship, inbreeding and generation interval in registered Gir cattle in Brazil. Journal of Animal Breeding and Genetics, v.110, p.228-233, 1993.

RAZOOK, A.G.; FIGUEIREDO, L.A.; BONILHA NETO, L.M.; TROVO, J.B.F.; PACKER, I.U.; PACOLA, L.J.; CÂNDIDO, J.G. Intensidades de seleção e respostas diretas e correlacionadas em 10 anos de progênies de bovinos das raças Nelore e Guzerá selecionadas para peso pós-desmame. Boletim Indústria Animal, v.50, p.147-163, 1993.

SÖLKNER, J.; FILIPCIC, L.; HAMPSHIRE, N. Genetic variability of populations and similarity of subpopulations in Austrian cattle breeds determined by analysis of pedigree. Animal Science, v.67, p.249-256, 1998.

VAN DER WERF, J. Inbreeding and the effects of increased prolificacy. In: KINGHORN, B.; VAN DER WERF, J.; RYAN, M. (Ed.). Animal breeding: use of new technologies. Armidale: University of New England, 2000. p.187-198.

VERCESI FILHO, A.E.; FARIA, F.J.C.; MADALENA, F.E.; JOSAHKIAN, L.A. Estrutura populacional do rebanho Tabapuã registrado no Brasil. Arquivo Brasileiro de Medicina Veterinária e Zootecnia, v.54, p.609-617, 2002.

VOZZI, P.A.; MARCONDES, C.R.; MAGNABOSCO, C. de U.; BEZERRA, L.A.F.; LÔBO, R.B. Structure and genetic variability in Nellore (Bos indicus) cattle by pedigree analysis. Genetics and Molecular Biology, v.29, p.482-485, 2006.

WEIGEL, K.A. Controlling inbreeding in modern breeding programs. Journal of Dairy Science, v.84, p.177-184, 2001. Supplement.

WRIGHT, S. Coefficients of inbreeding and relationships. American Naturalist, v.56, p.330-338, 1921. 